\title{
LA LITERATURA MARIANA Y LOS EJERCICIOS DEVOTOS DE SOR JUANA INÉS DE LA CRUZ
}

POR

\author{
CARMen L. MontañeZ \\ University of Kentucky
}

La obra literaria de Sor Juana Inés de la Cruz ha recobrado todo su valor durante el transcurso de todo este siglo XX y se ha convertido en una de las más geniales de la literatura hispanoamericana. Este interés por la obra literaria de Sor Juana, propulsada a principio de siglo por Amado Nervo con su libro Juana de Asbaje (1910), no se ha detenido en su obra profana, sino que en los últimos años ha surgido un vivo interés en su obra devota con igual ahínco. ${ }^{1}$ Ciertamente, no es para menos apreciar la riqueza literaria lograda en las loas, villancicos, sus letras sacras y en obras en prosa como Ofrecimiento para el Santo Rosario y Ejercicios devotos. Mucha de su literatura devota es a su vez literatura mariana. Un ejemplo de esta literatura mariana son los Ejercicios devotos para los nueve días de la Purísima Encarnación, ${ }^{2}$ los cuales nos interesa analizar con el objetivo de discutir el carácter literario; observar cómo funciona el texto dentro de la tradición ortodoxa mariana, haciendo un recuento breve de los orígenes de la doctrina mariana hasta el legado en América por los evangelizadores; qué o quiénes influyeron en Sor Juana para la escritura de los mismos; además observar los paralelismos con otros escritos marianos, prestando especial atención a la obra Mistica ciudad de Dios de la Madre María de Jesús de Agreda; y examinar qué motivos o conflictos indujeron a Sor Juana a escribir dichos ejercicios por medio del análisis del texto. ${ }^{3}$

Los orígenes de la doctrina mariana datan desde el comienzo del cristianismo con las Sagradas Escrituras, siendo Pablo el primero en mencionar a María en su carta a los Gálatas

\footnotetext{
${ }^{1} \mathrm{La}$ atracción hacia la obra literaria de Sor Juana ha impulsado a los críticos literarios a la investigación y estudio de la literatura creada por otras monjas durante la época colonial, incluyendo la creación religiosa y las autobiográficas, lo cual ha beneficiado considerablemente a la literatura colonial y esclarecido, así como confirmado, la situación de la mujer de esa época.

${ }^{2}$ Además de los Ejercicios devotos, Sor Juana dedica tres villancicos al tema de la Encarnación. Veáse Tres letras sueltas a la Encarnación en Obras completas de Sor Juana Inés de la Cruz (México: Editorial Porrúa, 1985) 314-316.

${ }^{3}$ Un artículo muy ilustrador sobre el tema tratado en este trabajo es el de Georgina Sabat de Rivers, "Ejercicios de la Encarnación: sobre la imagen de Marla y la decisión final de Sor Juana", en Estudios de literatura hispanoamericana: Sor Juana Inés de la Cruz y otros poetas barrocos de la Colonia (Barcelona: Promociones y Publicaciones Universales, S.A., 1992) 257-282. Este artículo está publicado también en Literatura Mexicana 1/2 (México D.F., 1990) 349-371.
} 
4, 5, al hablar sobre el nacimiento de Jesús. Mateo en su evangelio es más explícito y promulga los puntos o dogmas marianos: María la Madre de Dios que lo concibió por obra del Espíritu Santo. Lucas en sus escritos desarrolla estos dogmas y presenta a María como una mujer llena de gracia, que no conoce varón, conservadora de su virginidad, verdadera madre de Cristo y, por tanto, verdadera madre de Dios; como bendita entre las mujeres y que junto a los Apóstoles esperó al Espíritu Santo. Y es San Juan quien en el Apocalipsis 12 describe a la Virgen como una mujer vestida de sol, con la luna bajo sus pies y en su cabeza una corona de doce estrellas que combate exitosamente contra el dragón.

En el Concilio de Efeso en el año 431 se postula el pensamiento teológico mariano fundamentado en la maternidad y virginidad de María, estableciendo este Concilio un precedente a la investigación de la mariología patrística, según informan Javier Ibáñez y Fernando Mendoza en su obra María en la liturgía hispana (28).

En la Edad Media, el poeta dedicado al mester de clerecía, Gonzalo de Berceo, da un preámbulo al mundo literario mariano con sus obras Loores y Milagros de Nuestra Señora. Alfonso X con sus Cantigas de Santa María atestigua sobre la devoción mariana. También, Raimundo Lulio aporta a la literatura mariana sus obras Blanquerna, Hores de nostra Dona y otras, en catalán.

Los postulados marianos se integran y arraigan en España con afición en la forma más ortodoxa y luego son cimentados en América por los evangelizadores de la Iglesia. Así la literatura devota y mariana de Sor Juana tiene su razón de ser en la teología misma.

Afirma Josefina Muriel en su libro Cultura femenina novohispana al discutir la cultura y textos teológicos en la obra de Sor Juana lo siguiente:

El mundo en que vivió se explicaba con ideas teológicas. Ellas eran las que daban sentido a la existencia del hombre y las que ordenaban las acciones de la vida. El máximo de los estudios universitarios era entonces la teología, a la que todas las ciencias se subordinaban. Reina de las ciencias la llama Sor Juana (158).

Estas ideas teológicas sirvieron como base no sólo a Sor Juana, sino también a otros sacerdotes y monjas en la creación de sermones, novenas, triduos, estaciones del Vía Crucis, ejercicios espirituales y demás literatura devota. Podemos nombrar a Santo Tomás, San Ignacio de Loyola, Santa Teresa de Jesús y la Madre de Jesús de Agreda, para nombrar algunos.

Sor Juana demostró su devoción mariana por medio de su fructífero trabajo dedicado a la Virgen. Son los Ejercicios devotos para los nueve días antes de la Purísima Encarnación muestra eficiente de este fervor y dominio literario. Estos ejercicios están compuestos en prosa y dos poemas cortos. Los escribió entre 1684 y 1688, y fueron publicados en México. Aunque no se tiene una fecha exacta de su publicación, por la mención que hace Sor Juana sobre los Ejercicios en su Respuesta a Sor Filotea de la Cruz, se desprende que dicho documento mariano fue escrito mucho antes de $1691 .{ }^{4}$ Corresponden

\footnotetext{
${ }^{4}$ En Respuesta ... Sor Juana desea aclarar lo que se había imprimido sin o con su consentimiento, y sobre los Ejercicios devotos apunta: "de suerte que solamente unos Ejercicios de la Encarnación y unos $O$ frecimientos de los Dolores, se imprimieron con gusto mío por la pública devoción, pero sin mi nombre; de los cuales remito algunas copias ..." (Obras completas 847 ).
} 
estos ejercicios a nueve días continuos comenzando exactamente el 16 de marzo y terminando el 25 de marzo, fecha en la cual la Iglesia celebra el misterio de la Encarnación. De este modo Sor Juana tiene un fundamento eclesiástico para su escrito. Los ejercicios están estructurados en "Meditación", "Ofrecimiento" y "Ejercicios"; y para el primer día se incluye una "Dedicatoria" a la Virgen e "Introducción al Intento".

Los ejercicios corresponden a las creencias y dogmas que promulgaba la Iglesia, y aun promulga, en cuanto a los postulados teológicos marianos: la Asunción de la Virgen a los cielos, María como reina de los ángeles y María concebida sin pecado original. Además se ajustan a la literatura mariana convencional y tradicional, apoyándose en modelos aceptados y en las doctrinas que los padres de la Iglesia habían establecido. Por ejemplo, al hablar sobre las jerarquías celestiales se basa en la doctrina de San Gregorio para justificar su meditación de los días séptimo, octavo y noveno. Ésta es una forma de Sor Juana, como aclara Georgina Sabat de Rivers, utilizar el recurso de la "falsa modestia" y escapar de un posible enfrentamiento con la Inquisición (Sabat 264).

Aunque el intento y propósito de Sor Juana en sus ejercicios tienen un vínculo con los ejercicios de San Ignacio de Loyola manifestados en el Libro de ejercicios, existe una diferencia en su orientación. Los ejercicios de San Ignacio tienen el propósito de reenforzar y disciplinar las facultades como el entendimiento, la voluntad, el intelecto, la memoria y aficiones para lograr encontrarse a sí mismo y descubrir la voluntad de Dios; o sea, se orientan directamente a Dios. Los Ejercicios devotos creados por Sor Juana tienen el propósito de alabar, suplicar la intersección de la Virgen ante Dios y recordar, por medio de la Virgen, el misterio de la Encarnación. Este interés por lo mariológico por parte de Sor Juana marcan la diferencia orientadora.

Por otra parte, es de notar en los Ejercicios devotos el vínculo estrecho con la obra de la Madre de Jesús de Agreda, Mistica ciudad de Dios. ${ }^{5}$ Sor Juana en su "Introducción al intento" hace referencia en forma directa a la Madre de Jesús y su temática mariana será la misma que la de la Mistica ciudad de Dios. Ambas desarrollan su temática de las meditaciones diarias en base al Génesis, aplicando y desarrollando la creación del mundo paralelamente a los atributos divinos de la Virgen. Sobre esto nos aclara Josefina Muriel lo siguiente:

Si la temática de Sor Juana está basada en los escritos de la Madre de Jesús, no permanece apegada a ella, y es natural, pues la venerable María de Jesús escribe por inspiración mística, en tanto que Sor Juana lo hace por reflexión de su propio entendimiento (Muriel 159).

Para apreciar esta inspiración mística en la obra de la Madre Agreda, Mística ciudad de Dios, exponemos el comienzo del Libro Primero en el cual la Madre transcribe las palabras textuales de la Virgen:

\footnotetext{
${ }^{5}$ La Madre María de Jesús de Agreda o María Coronel y Arana nació el 2 de abril de 1602, en el pueblo de Agreda perteneciente al reino de Aragón. Para más datos sobre la Madre María véase de Manuel R. de Berlanga, Sor María de Agreda y su correspondencia con Felipe IV (Málaga, 1886). También en la edición de Carlos Seco Serrano, Cartas de Sor María de Jesús de Agreda y de Felipe IV (Madrid: Ediciones Atalas, 1958).
} 
Oyeme con atención, y Fé, que yo te hablaré palabra de vida eterna y te enseñaré lo más santo, y perfecto de la vida Cristiana, y lo más aceptable a los ojos de Dios; con que desde luego te comenzarás a disponer para recibir mi Vida Santísima, y la doctrina que deseas. Prosigue este exercicio, y escribirás lo que para ello te enseñaré (Agreda 2).

Ciertamente Sor Juana por carecer de la experiencia mística al nivel de Santa Teresa y la misma Madre Agreda, debe recurrir a sus conocimientos científicos ${ }^{6}$ para exaltar las virtudes de María en sus ejercicios. Un buen ejemplo de lo dicho es su "Meditación" del Día Segundo al referirse a María en forma alegórica:

Siempre conservó su firmeza, no sólo firme sino hermosa como el Firmamento, el cual (según los matemáticos) tiene esta excelencia más que los demás Orbes: y es que sólo está bordado de innumerables estrellas - tantas, que son todas las que vemos, sacando sólo siete planetas-, sino que las que tiene, todas son firmes y fijas, sin moverse, y en los otros cielos (con tener solo una) es errante; y siendo tan hermoso y transparente, goza estos más privilegios que no tienen los otros (Juana 851).

En la meditación del Día Cuarto al tratar sobre la creación del sol y la luna y afirmar cómo María era conocedora de toda la naturaleza y cualidades de todos los luminares, Sor Juana una vez más manifiesta su conocimiento sobre la ciencia astronómica:

Y la altísima sabiduría con que la gran señora conoció todas las naturalezas y cualidades de todos aquellos luminares: sus influjos, giros, movimientos, retrogresiones, eclipses, conjunciones, menguantes, crecientes y todos los efectos que pueden producir en los cuerpos sublunares, con perfectísima intuición? La generación de las lluvias, granizos, hielo y el espantoso aborto de los rayos? Sabiendo con clarísimo conocimiento todas las causas de estos admirables efectos que por tantos siglos han tenido suspensos y tan fatigados los entendimientos de los hombres en escrúpulos, sin llegar a tener perfecta ciencia de ellas(Juana. 854).

De forma escolástica Sor Juana entrelaza la ciencia y su amor mariológico para crear una obra devota. Como señala Josefina Muriel "Sor Juana lleva a alegoría mariana lo que para ella era una realidad científica” (Muriel 224).

No por ser los Ejercicios devotos de Sor Juana una obra devota pura carecen éstos del arte de escribir que caracteriza a Sor Juana en toda su obra literaria. Estos ejercicios son prosa poética o pasajes poéticos, expresados en su estilo barroco. Conocedora profunda

\footnotetext{
${ }^{6}$ Octavio Paz nos informa en su libro Sor Juana o las trampas de la fe (México: Fondo de Cultura Económica, 1982), al discutir el poema de Sor Juana "Primero Sueño", que la monja era una asidua lectora del padre Atanasio Kircher, al enunciar lo siguiente: "a mí me tocó atar los cabos y mostrar que la tradición hermética de la que es parte esencial la visión del alma liberada en el sueño de las cadenas corporales, llegó hasta Sor Juana a través de Kircher" (476). Kircher fue uno de los últimos representantes del hermetismo en el siglo XVII y que para escribir su Destino a la luna (Ixstaticum) siguió las teorías astronómicas de Tycho Brake, "un sistema en el que los planetas y las estrellas giran alrededor del Sol mientras éste y la Luna giran en torno a la Tierra" (Paz 478).
} 
de la Biblia, por sus estudios teológicos como mencionamos anteriormente, en la "Meditación" para los seis primeros días, Sor Juana fragmenta la creación según el elemento creado conforme al Génesis para presentarlos como tema de meditación. Estos temas se desarrollan en forma metafórica y simbólica con usos de símiles y adjetivaciones al relacionar dicho tema con la Virgen. En el Día Primero, en el "Ofrecimiento", donde se trata el tema de la creación de la luz, Sor Juana llama a la Virgen "luz más bella que la material, pues ilustráis los cielos con vuestro resplandor ..." (849). En el Día Segundo, en la "Meditación", al hablar sobre la creación del Firmamento, expresa sobre la Virgen "porque sola entre los hijos de Adán fue, como el Firmamento, criada entre las cristalinas corrientes de la gracia ..." (850). En el Día Tercero al tratar en la "Meditación" sobre la creación de las aguas, señala "Alegráronse las aguas congregadas ..." (852) y llama a la Virgen "mar de las perfecciones" (853). Además la llama Rosa de Jericó, Azucena de los Valles, expresando alegorías extraídas de la Biblia.

En el Día Cuarto al exponer en la "Meditación" la creación del sol, la luna y demás astros, otra vez en forma alegórica, Sor Juana expresa lo siguiente:

Vio el Sol a la que era más sola y escogida que sus luces, y la Luna a la que era más hermosa que su lucida candidez. Quisiérala vestir el Sol, como antes, pero hallábala iluminada del Sol de Justicia. Quisiera la Luna servirle de coturno, pero veía sus plantas elevadas, no sólo sobre el Empíreo, sino sobre todos los Coros Angélicos. Quisieran coronarla las Estrellas, pero coronábanla los rayos de la Divinidad de toda la Trinidad Santísima. ¿Qué sería ver el modo con que aquellas luminosas, aunque insensibles, criaturas dieron la obediencia a su reina? (853).

Como el tema principal de los ejercicios de Sor Juana es la creación del universo para rendir tributo a María, se ve ella precisada a evocar los elementos agua, tierra, aire y fuego como lo ha hecho en otras de sus obras, como por ejemplo en el Romance 19, "Lo atrevido de un pincel" (Juana 26). Es de notar como también Alfonso X, el Sabio, en sus cantigas hace uso de estos elementos. Referente a este asunto nos señala Jesús Montoya Martínez en su libro Las colecciones de milagros de la Virgen en la Edad Media al discutir las cantigas:

Otro grupo de cantigas, las de personalización de animales, animación de imágenes y aparición de María en sueños y visiones, aunque no exalta a María, son manifestaciones evidentes de que era "Señora en el aire, en el fuego, en el agua y en la tierra" (Montoya 119).

Al comienzo del "Ofrecimiento" del Día Cuarto abre la autora el mismo con la siguiente expresión:

¡Oh, Reina de la Sabidurla, más docta y sabia que aquella reina Sabá! Pues gozáis la enseñanza del verdadero Salomón, alcanzadnos de su Majestad la verdadera sabiduría, que es la virtud e inteligencia de las cosas celestiales, para encendernos en amor vuestro y de vuestro Hijo (854). 
A pesar del motivo religioso que tienen estos ejercicios no podemos pasar por alto al leer los pasajes de este Día Cuarto, el reflejo de los conflictos personales que tuvo Sor Juana por ser sabia. Los superiores de la Iglesia en forma directa e indirecta solicitaron de la monja el dedicarse a la vida normal de una religiosa y no a las letras. Este detalle se percibe en la Carta Atenagórica y luego en su Respuesta a Sor Filotea, donde Sor Juana tuvo el valor de defender su sabiduría y femineidad. En los Ejercicios ... nos dice que es María, una mujer, la más sabia, conocedora de todas las causas atmosféricas que en su época el hombre desconocía, al manifestar lo siguiente:

Sabiendo con clarísimo conocimiento todas las causas de estos admirables efectos que por tantos siglos han tenido suspensos y tan fatigados los entendimientos de los hombres, sin llegar a tener perfecta ciencia de ellas (854).

Nombrando así a una mujer excepcional que es más sabia que reinas terrenales reconocidas como sabias, y más sabia que los hombres de ciencia. Fue María para Sor Juana una inspiración para poner en función su talento y reconocerse a sí misma como sabia, y en especial, reconocer que su talento literario era un don divino. La Iglesia reconocía - y aún reconoce - en María el don de la obediencia pues se instaba - y aun se hace- a la mujer a seguirla como modelo en esta capacidad, y Sor Juana no sólo desea tenerla como modelo de obediencia, sino como modelo de sabiduría a quien los hombres, animales y todos los coros y jerarquías celestiales y terrenales deben obediencia. De esta forma, una vez más, Sor Juana trae a colación el tema de la mujer en una forma indirecta e inintencionada, pero que nunca pudo evitar.

Por otro lado, es de notar en estas "Meditaciones" que la presencia de Eva en la creación está excluida. La creación de la mujer es un hecho englobado dentro de la creación del hombre contrastando esta síntesis con la versión del libro 3 del Génesis. Sor Juana llama al hombre rey del universo y a Adán lo caracteriza específicamente como monarca de todo lo creado; pero a la vez considera a Adán culpable y responsable de la falta, contrario a lo establecido de que fue Eva la iniciadora de la acción fatal que les arrojaría del paraíso:

Porque habiendo creado a Adán en justicia original y gracia, le crió por monarca de todo lo criado en el mundo, $y$ todas las criaturas inferiores le dieron obediencia, hasta que por la culpa y haber él quebrantado la que a Dios debía, le fue alzada de sus inferiores, rebelándose contra él los elementos y demás criaturas (856).

Es factible que Sor Juana en su visión femenina no aceptó del todo la enseñanza tradicional de que fue la mujer la incitadora al pecado, sino que consideró y visualizó la falta del hombre en su acepción semántica. $O$, posiblemente, no consideró a Eva digna de equipararse a otra mujer como María, ya que para Sor Juana, siguiendo la doctrina de la Iglesia, María fue preservada del pecado original o a lo que ella se refiere como "original ponzoña" (856).

Sor Juana da un rol femenino único a la Virgen antes y después de la creación del universo, dándole así seguimiento a la Madre de Jesús de Agreda que en el Libro Séptimo, 
Doctrina II de la Mistica ciudad de Dios, expone la explicación de María sobre la visión que tuvo Juan en el Apocalipsis cuando la vio descender del cielo:

Hija mía, quierote manifestar, para tu aliento, y de mis siervos, que has escrito los Misterios de estos Capítulos con agrado, y aprobación del Altísimo, cuya voluntad es, el manifestarle al mundo lo que Yo hize por la Iglesia, bolviendo a ella desde el Cielo Empyreo, para ayudar a los Fieles (Agreda 482).

Sor Juana reafirma este acontecimiento en sus ejercicios en la "Introducción al intento", cuando hace mención de los relatos de la Virgen a la Madre Agreda:

Entre ellos fue mostrarle toda la creación del Universo, haciendo que todas aquellas criaturas las fuesen jurando reina y dándole la obediencia, y después, subiéndola por tres veces al Cielo, siendo la tercera en cuerpo y alma (848).

Apreciamos pues en toda esta argumentación cómo Sor Juana, a pesar de creer en los dogmas de la Iglesia, no se adhirió al criterio racionalizador ortodoxo acerca de la inferioridad femenina dentro de la jerarquía eclesiástica. Una vez más Sor Juana da señas de su conflicto interior y se topa frente a frente entre la razón y su amor religioso, como en muchas otras ocasiones. Son estos ejercicios espirituales una forma aparente de exorcismo de parte de Sor Juana, para dar paso a su vocación religiosa y devoción a la Virgen; aunque no desistió en amalgamar sus conflictos y la religión.

Estos ejercicios marianos son un acto de obediencia y humildad de parte de Sor Juana no sólo para con Dios y la Virgen, sino también ante la jerarquía eclesiástica terrenal, según se aprecia en la "Dedicatoria" al comienzo de los ejercicios:

El dedicar esta obra a vuestros reales y sagrados pies, bien sabéis vos que no es ofrenda sólo voluntaria, sino también restitución debida, por ser vuestra antes que mía; no sólo por lo sagrado del asunto, sino porque vos, Princesa Inmaculada, os servísteis de inspirar a algunas almas devotas que me la mandasen disponer: con que no le queda de mía sino la rústica corteza y el torpe estilo en que va escrita; de lo cual pido perdón a vuestra maternal clemencia (848).

Sor Juana no intenta escribir una obra que se adapte y se someta rigurosamente a los cánones literarios, sino que obedecerá los deseos de la Virgen que por medio de otras personas, probablemente su confesor, se lo ha solicitado. A la vez se humilla ante María por no encontrarse digna de meditar en tan "altos misterios" y con modestia califica a este acto de escribir una osadía "en mi inmunda boca y mi baja pluma" (848). Más adelante, en la "Meditación" para el "Día de la Encarnación" manifiesta, "este día, más era para un doctísimo panegirista, para un elocuentísimo orador, para un elegantísimo retórico, que para el débil instrumento de mi discurso" (864). Pero sin embargo, luego de este acto de humildad Sor Juana reflexiona profundamente sobre el concepto "Madre de Dios" como una doctosísima marianista.

Es así como Sor Juana por medio de su literatura mariana nos muestra que ella aspiraba a crear una literatura como le exigía su estado y que era capaz de crearla. Fue para el 5 de 
marzo de 1694, según informa Octavio Paz en su obra Sor Juana o las trampas de la fe, siguiendo el relato del Padre Callejas, que Sor Juana por medio de otro documento mariológico, abdica de los estudios humanos para seguir el camino de la perfección ( $\mathrm{Paz}$ 596). ${ }^{7}$ Consideramos que esta renuncia es el acto de obediencia por excelencia por parte de Sor Juana que por consiguiente implicaba un gran sacrificio.

Los Ejercicios devotos de Sor Juana Inés de la Cruz, aunque carecen del misticismo clásico de otros ejercicios, son humanizados y racionalizados, pero devotos y llenos de fe. Igualmente, son testimonio del dominio de la lengua del que siempre gozó la autora mexicana, como bien lo ha demostrado en todos sus escritos. En estos ejercicios expresa Sor Juana una realidad histórica integrada en la fe; y para ella, la mujer tiene una importancia vital en su mundo religioso. Por medio de esta obra mariana, una vez más Sor Juana sigilosamente expone a la mujer a través de María, como un ser sabio, capaz de llevar a cabo cualquier encomienda, ya sea ésta dentro de una jerarquía celestial o terrenal.

\section{ObRas citadAs}

Agreda, María de Jesús, de. Escuela mística de María Santísima en la mistica ciudad de Dios. México: José Bernardo de Hogal, 1731.

Arenal, Electa. "The Convent as Catalyst for Autonomy: Two Hispanic Nuns of the Seventeenth Century". Women in Hispanic Literature: Icons and Fallen Idols. Beth Miller, editora. Berkeley: University of California Press, 1983. 147-183.

Egan, Harvey D., S. J. The Spiritual Exercises and the Ignatian Mystical Horizon. St. Louis: The Institute of Jesuist Sources, St. Louis University, 1976.

Ibáñez, Javier, y Fernando Mendoza. Maria en la liturgia hispana. Pamplona: Ediciones Universidad de Navarra, 1975.

Montoya Martínez, Jesús. Las colecciones de milagros de la Virgen en la Edad Media. España: Universidad de Granada, 1981.

Muriel, Josefina. Cultura femenina novohispana. México: UNAM, 1982.

Juana Inés de la Cruz. Ejercicios devotos. Obras completas. Prólogo de Francisco Monterde. México: Editorial Porrúa, 1985. 848-866.

Paz, Octavio. Sor Juana Inés de la Cruz o las trampas de la fe. Barcelona: Seix Barral, 1982.

Sabat de Rivers, Georgina. "Ejercicios de la Encarnación: sobre la imagen de María y la decisión final de Sor Juana". Literatura Mexicana 1:2 (México, D.F., 1990): 349371. Estudios de literatura hispanoamericana (Barcelona: PPU, 1992): 257-282.

\footnotetext{
7 Véase también en Obras completas (México: Editorial Porrúa 1969) bajo el subtítulo "Protesta", 873-874.
} 